\title{
A comparison of three measures of perceived distress: results from a study of angina patients in general practice in Northern Ireland
}

\author{
C O’Neill, C Normand, M Cupples, A McKnight
}

\begin{abstract}
Objective - To establish the effect of health education on the level of distress felt by patients with angina and to compare the results obtained using different measures. Design - Randomised controlled trial of personal health education given every four months.
\end{abstract}

Setting - Eighteen general practices in the greater Belfast area.

Subjects - These comprised 688 patients aged less than 75 years and known to have had angina for at least six months: 342 were randomised to receive education and 346 no education.

Main outcome measures - These were the Nottingham health profile (NHP), functional limitation profile (FLP), and a simple categorical scale (SCS).

Results - The intervention group showed a statistically significant improvement in health relative to the control group in terms of physical mobility and social isolation using the NHP. In terms of overall wellbeing, both the NHP and SCS results showed the intervention group had experienced statistically significant improvements in health relative to the control group. Results obtained using the NHP, FLP, and SCS were found to be correlated regardless of whether weighted or unweighted scores were used.

Conclusion - The intervention produced a significant improvement in health status. Results from different survey instruments were correlated using both weighted and unweighted scores. An SCS was capable of detecting the improvement in health status.

(f Epidemiol Community Health 1996;50:202-206)

The need for outcome measures in health care is well documented, ${ }^{1-4}$ as is the multidimensional nature of that need. ${ }^{5} \mathrm{~A}$ considerable volume of work has been directed at the development and testing of a variety of measures. (See reference ${ }^{6}$ for a recent review.) Indeed such is the volume of ongoing work that a substantial part of one publication is devoted to reporting new publications. ${ }^{7}$

Some comparative studies ${ }^{89}$ indicate that the instrument used to measure outcome may influence the result obtained, a fact which has also been noted by other authors. ${ }^{510}$ Given the variety of measures available, the assertion by many that no gold standard exists for current measures $^{21112}$ and that new measures are continually emerging, ${ }^{13-16}$ researchers are understandably cautious in drawing inferences from results obtained using a single instrument. Some indeed argue that "the use of a single quality of life measure in isolation . . . should be avoided".

A study of patients with angina in general practice examined the effect of personal health education on the quality of their lives. ${ }^{17}{ }^{15}$ Quality of life was measured using three different instruments. The results from the study were then used to:

- Establish the effect of the intervention on perceived distress and validate these results;

- Examine relationships between the three measures at baseline and between two of the measures after the intervention;

- Establish the capacity of a simple categorical scale (SCS) to pick up changes in quality of life; and

- Investigate the value of using weighted versus unweighted scores.

\section{Method}

One hundred and one patients diagnosed as having angina were selected at random to receive three quality of life measures. (Sample selection and characteristics are discussed in greater detail elsewhere. ${ }^{17}{ }^{15}$ ) The three measures used were the Nottingham health profile (NHP), ${ }^{18-20}$ the functional limitation profile (FLP), ${ }^{21-23}$ and a simple categorical scale (SCS). The latter offered the respondent five possible descriptions of their health status ranging from poor $=1$ to very good $=5$ with which they could agree. Responses to this were collected as part of a questionnaire relating to general information about the individual's age, occupation, medical history, etc. This questionnaire was administered verbally and responses were recorded by the research worker. The NHP and FLP questionnaires were filled in by the subject immediately after this and in the order presented.

Analysis of the 101 responses (discussed below) suggested that the three instruments, while not interchangeable, produced essentially similar results in terms of how individuals were ranked by both global and, where appropriate, profile scores. The FLP was the longest and most complex of the three instruments used. Given the similarity in results obtained from the three measures, applied to 101 respondents, the additional gains from using the FLP in 
Table 1 Descriptive statistics for the sample using the Nottingham health profile (NHP), the functional limitation profile (FLP), and the simple categorical scale (SCS)

\begin{tabular}{|c|c|c|c|c|c|}
\hline & Item & Mean & Median & $(S D)$ & (Range) \\
\hline \multirow[t]{7}{*}{ NHP } & $\begin{array}{l}\text { Global W } \\
\text { Global Uw }\end{array}$ & $\begin{array}{r}168 \cdot 51 \\
11 \cdot 75\end{array}$ & $\begin{array}{r}147 \cdot 12 \\
10 \cdot 00\end{array}$ & $\begin{array}{r}(128 \cdot 71) \\
(8 \cdot 37)\end{array}$ & $\begin{array}{l}(0-449 \cdot 46) \\
(0-31 \cdot 0)\end{array}$ \\
\hline & $\begin{array}{l}\text { Pain W } \\
\text { Pain Uw }\end{array}$ & $\begin{array}{r}23 \cdot 22 \\
2 \cdot 19\end{array}$ & $\begin{array}{r}17 \cdot 05 \\
2 \cdot 00\end{array}$ & $\begin{array}{r}(23 \cdot 56) \\
(2 \cdot 05)\end{array}$ & $\begin{array}{l}(0-100) \\
(0-8)\end{array}$ \\
\hline & $\begin{array}{l}\text { Mobility W } \\
\text { Mobility Uw }\end{array}$ & $\begin{array}{r}22 \cdot 83 \\
2 \cdot 11\end{array}$ & $\begin{array}{r}21 \cdot 36 \\
2 \cdot 00\end{array}$ & $\begin{array}{r}(21.87) \\
(1.98)\end{array}$ & $\begin{array}{l}(0-78 \cdot 70) \\
(0-7)\end{array}$ \\
\hline & $\begin{array}{l}\text { Energy W } \\
\text { Energy Uw }\end{array}$ & $\begin{array}{r}47 \cdot 33 \\
1.50\end{array}$ & $\begin{array}{r}60 \cdot 80 \\
2 \cdot 00\end{array}$ & $\begin{array}{r}(39 \cdot 88) \\
(1 \cdot 18)\end{array}$ & $\begin{array}{l}(0-100) \\
(0-3)\end{array}$ \\
\hline & $\begin{array}{l}\text { Emotions W } \\
\text { Emotions Uw }\end{array}$ & $\begin{array}{r}22 \cdot 20 \\
2 \cdot 23\end{array}$ & $\begin{array}{r}13.95 \\
1.00\end{array}$ & $\begin{array}{r}(24 \cdot 14) \\
(2 \cdot 31)\end{array}$ & $\begin{array}{l}(0-86 \cdot 01) \\
(0-8)\end{array}$ \\
\hline & $\begin{array}{l}\text { Social W } \\
\text { Social Uw }\end{array}$ & $\begin{array}{r}10 \cdot 88 \\
0 \cdot 52\end{array}$ & $\begin{array}{l}0 \cdot 00 \\
0 \cdot 00\end{array}$ & $\begin{array}{r}(21.33) \\
(1.04)\end{array}$ & $\begin{array}{l}(0-100) \\
(0-5)\end{array}$ \\
\hline & $\begin{array}{l}\text { Sleep W } \\
\text { Sleep Uw }\end{array}$ & $\begin{array}{r}41 \cdot 04 \\
2 \cdot 23\end{array}$ & $\begin{array}{r}34 \cdot 27 \\
2 \cdot 00\end{array}$ & $\begin{array}{r}(36.45) \\
(1.80)\end{array}$ & $\begin{array}{l}(0-100) \\
(0-5)\end{array}$ \\
\hline \multirow[t]{8}{*}{ FLP } & $\begin{array}{l}\text { Global W } \\
\text { Global Uw }\end{array}$ & $\begin{array}{r}1103 \cdot 60 \\
16.00\end{array}$ & $\begin{array}{r}1052 \\
19\end{array}$ & $\begin{array}{r}(638 \cdot 06) \\
(9 \cdot 72)\end{array}$ & $\begin{array}{l}(56-2828) \\
(5-43)\end{array}$ \\
\hline & $\begin{array}{l}\text { Household W } \\
\text { Household Uw }\end{array}$ & $\begin{array}{r}200 \cdot 33 \\
3 \cdot 34\end{array}$ & $\begin{array}{r}212 \\
3\end{array}$ & $\begin{array}{r}(149 \cdot 36) \\
(2 \cdot 24)\end{array}$ & $\begin{array}{l}(0-574) \\
(0-8)\end{array}$ \\
\hline & $\begin{array}{l}\text { Rec\&P W } \\
\text { Rec\&P Uw }\end{array}$ & $\begin{array}{r}73 \cdot 74 \\
1.94\end{array}$ & $\begin{array}{r}68 \\
2\end{array}$ & $\begin{array}{r}(66.83) \\
(1.67)\end{array}$ & $\begin{array}{l}(0-272) \\
(0-6)\end{array}$ \\
\hline & $\begin{array}{l}\text { Ambulation W } \\
\text { Ambulation Uw }\end{array}$ & $\begin{array}{r}164 \cdot 51 \\
2 \cdot 75\end{array}$ & $\begin{array}{r}155 \\
3\end{array}$ & $\begin{array}{r}(134.09) \\
(1.95)\end{array}$ & $\begin{array}{l}(0-608) \\
(0-8)\end{array}$ \\
\hline & $\begin{array}{l}\text { Mobility W } \\
\text { Mobility Uw }\end{array}$ & $\begin{array}{r}95 \cdot 89 \\
1.59\end{array}$ & $\begin{array}{r}52 \\
1\end{array}$ & $\begin{array}{r}(111.67) \\
(1.81)\end{array}$ & $\begin{array}{l}(0-372) \\
(0-6)\end{array}$ \\
\hline & $\begin{array}{l}\text { Sleep W } \\
\text { Sleep Uw }\end{array}$ & $\begin{array}{r}80 \cdot 87 \\
1.07\end{array}$ & $\begin{array}{r}62 \\
1\end{array}$ & $\begin{array}{r}(102 \cdot 92) \\
(1 \cdot 28)\end{array}$ & $\begin{array}{l}(0-505) \\
(0-6)\end{array}$ \\
\hline & $\begin{array}{l}\text { Social W } \\
\text { Social Uw }\end{array}$ & $\begin{array}{r}164 \cdot 79 \\
3 \cdot 32\end{array}$ & $\begin{array}{r}108 \\
2\end{array}$ & $\begin{array}{r}(178 \cdot 71) \\
(3 \cdot 24)\end{array}$ & $\begin{array}{l}(0-925) \\
(0-16)\end{array}$ \\
\hline & $\begin{array}{l}\text { Work } \mathrm{W}^{*} \\
\text { Work Uw* }\end{array}$ & $\begin{array}{r}323.48 \\
1.99\end{array}$ & $\begin{array}{r}417 \\
2\end{array}$ & $\begin{array}{r}(151 \cdot 45) \\
(0 \cdot 85)\end{array}$ & $\begin{array}{c}(56-458)^{*} \\
(1-7)\end{array}$ \\
\hline SCS & & 3.060 & 3 & $(1 \cdot 0325)$ & $(1-5)$ \\
\hline
\end{tabular}

* Some individuals exceeded the notional maximum score as a result of an inconsistency in their responses, responding that they no longer worked but later describing their daily work as being light. $\mathrm{W}=$ weighted score; $\mathrm{Uw}=$ unweighted score.

Table 2 Correlation between the Nottingham health profile (NHP) and the functional limitation profile (FLP) scores in relation to profile aspect

\begin{tabular}{|c|c|c|c|c|}
\hline \multirow{2}{*}{$\begin{array}{l}\text { Profile aspect } \\
(F L P / N H P)\end{array}$} & \multicolumn{2}{|c|}{ Spearman's rank correlation coefficient } & \multicolumn{2}{|l|}{$Z$ value } \\
\hline & Weighted & Unweighted & Weighted & Unweighted \\
\hline Sleep/sleep & 0.45 & 0.49 & $4 \cdot 5^{*}$ & $4 \cdot 9 *$ \\
\hline Mobility/mobility & 0.65 & 0.65 & $6 \cdot 5^{*}$ & $6 \cdot 5^{*}$ \\
\hline Social/social & 0.51 & 0.52 & $5 \cdot 1^{*}$ & $5 \cdot 2^{*}$ \\
\hline Ambulation/mobility & 0.65 & 0.62 & $6 \cdot 5^{*}$ & $6 \cdot 2^{*}$ \\
\hline
\end{tabular}

* Significant correlation at $\mathrm{p}<0.0001 ; \mathrm{n}=101$.

terms of useful information were not felt to warrant the additional resources that applying it would require. As a result only the NHP and SCS were applied in a larger survey involving a further 587 patients.

For the same reasons, at the end of the trial, all survivors received only the NHP and the SCS questionnaires to detect the effect of the intervention on the individual's quality of life.

\section{STATISTICAL METHODS}

Given the role of scaling in affecting the magnitude of results ${ }^{2425}$ and in line with the Nottingham Health Profile User's Manual ${ }^{26}$ nonparametric approaches were taken when examining the results. For the 101 baseline responses, correlations between similar aspects of profile for the NHP and FLP and between global scores, both weighted and unweighted, were tested using Spearman's rank correlation test. The global score of the NHP was arrived at by a simple aggregation of its component parts rather than by the use of the 24 item distress index. ${ }^{27}$ There are difficulties in interpreting aggregated profile scores. ${ }^{6}$ Here, a higher aggregate score, weighted or unweighted, is interpreted as being associated with greater distress/illness in both FLP and NHP instruments. It is in this broad sense only that global scores are interpreted and comparisons of them made.

The relationship between responses to the simple categorical scale and those to the NHP and FLP were investigated using ordered probit analysis, ${ }^{28}$ and the significance of the association between responses to individual questions, which given their content one would expect to be correlated, was tested using $\chi^{2}$ tests on unweighted responses.

For the larger sample the correlation between changes in the NHP weighted and unweighted scores and changes in the SCS scores for each individual were examined using Spearman's rank correlation test. Finally, the effect of the intervention on perceived quality of life was assessed using a Mann-Whitney-Wilcoxon sum of ranks test for both weighted and unweighted scores for both the NHP and SCS.

\section{Results}

Various summary statistics for NHP, FLP, and the SCS for the 101 people who completed all three questionnaires are reported in table 1 . As can be seen from table 1 , a wide range of values was recorded using all three survey instruments indicating that a wide range of distress was represented in the sample. Inferences made concerning the comparability of instruments are therefore likely to be more reliable than would be the case were, for example, only those at one end of the distress scale observed in the sample.

Table 2 shows the results of Spearman's rank correlation tests comparing the NHP and FLP scores on aspects of the profile which, tapping the same domain of health/distress, one would expect to be correlated. The correlations between both weighted and unweighted scores are reported. As can be seen, each aspect of the profile which one might expect to be significantly correlated was found to be so. The use of weights here did not affect results.

Table 3 gives the results of a selection of ordered probit analyses of categorical scale scores on NHP and FLP weighted and unweighted profile and global scores (the form of the model used is indicated in each instance). The significant $\mathrm{t}$ and $\chi^{2}$ values here show profile scores to be significant determinants of the SCS score - that is, a high correlation between the SCS and other survey instruments is seen to exist.

Table 4 examines whether statistically significant matching of responses occurred between responses to two specific FLP questions and NHP counterparts one would expect to be tapping the same domain of health. Significant $\chi^{2}$ values here indicate significant correlations between responses by individuals to these specific questions - a type of construct validation.

Finally, table 5 details the changes in quality of life associated with the intervention obtained using the NHP and SCS and the correlation which existed between these measures. 
Table 3 Ordered probit analyses of simple categorical scale (SCS) scores on Nottingham health profile (NHP) and functional limitation profile (FLP) scores

\begin{tabular}{|c|c|c|c|}
\hline & $\mu_{I}$ & $\mu_{2}$ & $\mu_{3}$ \\
\hline $\begin{array}{l}\mathrm{SCS}=2.9713-0.0061 \text { NglobalW; } \\
\begin{array}{l}(8.54)(6.43) \\
\chi^{2} \text { value }=42.01\end{array}\end{array}$ & $\begin{array}{l}1 \cdot 1723 \\
(4.92)\end{array}$ & $\begin{array}{l}2 \cdot 6692 \\
(9 \cdot 56)\end{array}$ & $\begin{array}{l}3.5528 \\
(11.49)\end{array}$ \\
\hline $\begin{array}{l}\mathrm{SCS}=2.9503-0.0885 \mathrm{Nglobal} ; \\
\quad(8.396)(5.992) \\
\chi^{2} \text { value }=38.90\end{array}$ & $\begin{array}{l}1 \cdot 1459 \\
(4 \cdot 94)\end{array}$ & $\begin{array}{l}2 \cdot 6111 \\
(9 \cdot 64)\end{array}$ & $\begin{array}{l}3.4830 \\
(11.72)\end{array}$ \\
\hline $\begin{array}{l}S C S=2 \cdot 1643-0 \cdot 2396 \text { Nmobility; } \\
\quad(7 \cdot 20)(3 \cdot 70) \\
\chi^{2} \text { value }=18 \cdot 33\end{array}$ & $\begin{array}{l}0.9787 \\
(4.53)\end{array}$ & $\begin{array}{l}2 \cdot 2635 \\
(8 \cdot 69)\end{array}$ & $\begin{array}{l}3.0789 \\
(11 \cdot 14)\end{array}$ \\
\hline $\begin{array}{l}\mathrm{SCS}=2 \cdot 1780-0 \cdot 0223 \text { NmobilityW; } \\
\quad(7 \cdot 29)(3 \cdot 74) \\
\chi^{2} \text { value }=19 \cdot 19\end{array}$ & $\begin{array}{l}0.9872 \\
(4.55)\end{array}$ & $\begin{array}{l}2 \cdot 2779 \\
(8 \cdot 72)\end{array}$ & $\begin{array}{l}3 \cdot 0945 \\
(11 \cdot 16)\end{array}$ \\
\hline $\begin{array}{l}\mathrm{SCS}=2 \cdot 7073-0 \cdot 3800 \text { Nsleep; } \\
(7 \cdot 11)(5 \cdot 14) \\
\chi^{2} \text { value }=33 \cdot 75\end{array}$ & $\begin{array}{l}1 \cdot 1186 \\
(4 \cdot 53)\end{array}$ & $\begin{array}{l}2 \cdot 5477 \\
(8 \cdot 24)\end{array}$ & $\begin{array}{l}3.3846 \\
(10 \cdot 32)\end{array}$ \\
\hline $\begin{array}{l}\mathrm{SCS}=2 \cdot 6861-0.0192 \text { NsleepW; } \\
(7.07)(5 \cdot 20) \\
\chi^{2} \text { value }=34.88 \\
\mathrm{SCS}=\mathrm{f}(\text { constant, FLP score })\end{array}$ & $\begin{array}{l}1 \cdot 1368 \\
(4 \cdot 50)\end{array}$ & $\begin{array}{l}2 \cdot 5739 \\
(8 \cdot 18)\end{array}$ & $\begin{array}{l}3 \cdot 4104 \\
(10 \cdot 27)\end{array}$ \\
\hline $\begin{array}{l}\mathrm{SCS}=2.9964-0.0720 \text { globalU; } \\
\begin{array}{c}(8.02) \\
\chi^{2} \text { value }=35.5\end{array}\end{array}$ & $\begin{array}{l}1 \cdot 0784 \\
(5 \cdot 11)\end{array}$ & $\begin{array}{l}2 \cdot 5272 \\
(9 \cdot 86)\end{array}$ & $\begin{array}{l}3.4049 \\
(11 \cdot 75)\end{array}$ \\
\hline $\begin{array}{l}\mathrm{SCS}=1.0698-0.0005 \text { global; } \\
(3.38)(0.29) \\
\chi^{2} \text { value }=15 \cdot 16\end{array}$ & $\begin{array}{l}0 \cdot 8607 \\
(4 \cdot 64)\end{array}$ & $\begin{array}{l}2 \cdot 0138 \\
(8 \cdot 35)\end{array}$ & $\begin{array}{l}2 \cdot 7687 \\
(10 \cdot 17)\end{array}$ \\
\hline $\begin{array}{l}\mathrm{SCS}=2 \cdot 3744-0.3536 \text { mobilityU; } \\
\quad(7 \cdot 54)(4 \cdot 86) \\
\chi^{2} \text { value }=30 \cdot 30\end{array}$ & $\begin{array}{l}1.0784 \\
(4.93)\end{array}$ & $\begin{array}{l}2 \cdot 4770 \\
(9 \cdot 04)\end{array}$ & $\begin{array}{l}3.3113 \\
(10.93)\end{array}$ \\
\hline $\begin{array}{l}S C S=2 \cdot 3962-0.0059 \text { mobility; } \\
(7 \cdot 87)(5 \cdot 00) \\
\chi^{2} \text { value }=31 \cdot 88\end{array}$ & $\begin{array}{l}1.0923 \\
(4 \cdot 98)\end{array}$ & $\begin{array}{l}2 \cdot 5041 \\
(9 \cdot 16)\end{array}$ & $\begin{array}{l}3.3428 \\
(11.08)\end{array}$ \\
\hline $\begin{array}{l}\mathrm{SCS}=2 \cdot 1214-0 \cdot 4038 \text { sleepU; } \\
(7 \cdot 40)(3 \cdot 39) \\
\chi^{2} \text { value }=21 \cdot 49\end{array}$ & $\begin{array}{l}0.9866 \\
(4 \cdot 67)\end{array}$ & $\begin{array}{l}2 \cdot 3066 \\
(8 \cdot 48)\end{array}$ & $\begin{array}{l}3 \cdot 1399 \\
(10 \cdot 45)\end{array}$ \\
\hline $\begin{array}{c}S C S=2.0781-0.0049 \text { sleep; } \\
\quad(7.51)(3.43) \\
\chi^{2} \text { value }=20 \cdot 46\end{array}$ & $\begin{array}{l}0.9865 \\
(4 \cdot 69)\end{array}$ & $\begin{array}{l}2 \cdot 2952 \\
(8 \cdot 59)\end{array}$ & $\begin{array}{l}3 \cdot 1214 \\
(10 \cdot 55)\end{array}$ \\
\hline
\end{tabular}

Table 4 Comparison of responses to specific Nottingham health profile (NHP) and functional limitation profile (FLP) questions

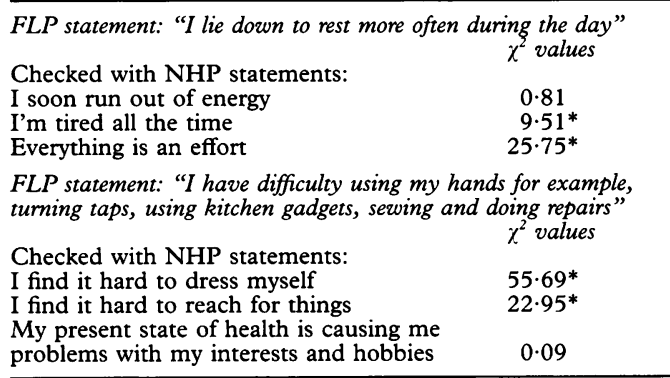

* No significant difference between expected and observed frequencies at $\mathrm{p}<0 \cdot 01$.

Table 5 Changes in health status for control and intervention groups

\begin{tabular}{lllll}
\hline Profile aspect & $\begin{array}{l}\text { Intervention } \\
\text { group mean diff }\end{array}$ & $\begin{array}{l}\text { Control group } \\
\text { mean diff }\end{array}$ & MWW & Probability \\
\hline Physical mobility & -1.49 & -6.19 & -2.9357 & 0.0015 \\
Social isolation & +1.42 & -3.01 & -1.7412 & 0.0408 \\
Emotional reaction & -0.79 & -1.91 & -0.6434 & 0.2600 \\
Energy & -3.88 & -6.52 & -0.9741 & 0.165 \\
Sleep & -1.67 & -0.10 & -0.8637 & 0.1938 \\
Pain & -1.23 & -2.70 & -0.1018 & 0.4594 \\
Total & -7.64 & -20.43 & -1.5069 & 0.0659 \\
SCS & -0.211 & -0.01 & -2.3154 & 0.0206 \\
Spearman's rank correlation coefficient for & SCS with aspects of NHP &
\end{tabular}

Spearman's rank correlation coefficient for SCS with aspects of NHP

\begin{tabular}{lll}
\hline Profile & Coefficient & Probability \\
\hline Global & -0.1949 & 0.000 \\
Pain & -0.0505 & 0.147 \\
Mobility & -0.1142 & 0.009 \\
Energy & -0.1404 & 0.002 \\
Emotions & -0.2255 & 0.000 \\
Social & -0.1980 & 0.000 \\
Sleep & -0.0237 & 0.311 \\
\hline
\end{tabular}

$\mathrm{n}=221$ for intervention group; 212 for control group.

MWW = Mann-Whitney-Wilcoxon sum of ranks test; $\mathrm{SCS}=$ simple categorical scale; NHP= Nottingham health profile.

\section{Discussion}

As reported in table 1 , a wide range of perceived distress/health was observed within the sample, underlining the relevance of the results obtained. The significant correlations reported in table 2 between the NHP and FLP, in table 3 between the SCS and NHP and between the SCS and FLP, and in table 5 between changes in the NHP and SCS, indicate that the three instruments are consistent in terms of their relative evaluations of health status and changes in health status. While the correlation between NHP and FLP for perceived changes in health status could not be estimated (as no follow up FLP was conducted) the results reported suggest that there is no reason to believe the latter instrument would have produced results which differed in any useful way (in terms of the impact of the intervention) from those reported. That is, all the evidence tends to support the argument that the particular intervention involved did produce the change in perceived health status indicated in table 5, both in terms of those domains of health covered and in global terms.

As both the NHP and FLP are tried and tested survey techniques, the consistency of the results obtained using them is perhaps not surprising. Nevertheless, establishing this consistency as opposed to assuming it remains a valuable exercise in itself and adds weight to the case that the particular intervention involved has impacted on the quality of life in the manner described.

The consistency in the results obtained, regardless of the length and complexity of the questionnaire used, suggests significant efficiency gains may be had from using relatively simple questionnaires. That is, where the aim is to establish if an intervention improves the quality of life without establishing which particular aspect it improves, the shortest of survey instruments may be sufficient.

Of course, this is not to say that instruments are interchangeable. That is, as noted elsewhere, ${ }^{2912}$ the implicit efficiency gains in terms of interviewer time and decreased likelihood of non-response bias are not obtained without a cost in terms of the loss in detail which lengthier questionnaires give. While the SCS may capture overall wellbeing as effectively as (say) the FLP, details on whether it was, for example, aspects of mobility, social interaction, or sleep which contributed to feelings of distress cannot be identified from the shorter questionnaire.

Where detail is not required, where resources for conducting quality of life surveys are severely restricted, or where the nature of the illness may not make detailed questionnaires feasible (for example, in cases of mild dementia) these short forms may, nevertheless, be useful.

Similarly, with reference to the NHP and FLP, while the former may be shorter than the latter, and in this instance produce correlated results, it should be remembered that these instruments do cover different domains of health/distress. Consequently, in instances where particular domains such as pain are important - for example, in arthritis - the degree 
of correlation in global scores reported here may not be as apparent (this domain is absent from the FLP). This only serves to emphasise the fact that to obtain useful results, instruments must be applied and results interpreted in a sensible manner.

Finally, the manner in which the instruments were applied - that is, consecutively within a single interview - should also be noted here. We did not attempt to establish if the order in which instruments were applied affected results, either in terms of the scores recorded on each instrument or the consistency between the scores on different instruments. Similarly, it is accepted that the interpretations attached to different questions on different instruments may have been other than would have been the case had the instruments been applied in isolation. This point notwithstanding, it seems unlikely, given the instruments investigate similar aspects of health/distress, that the order in which they are offered would greatly alter the responses obtained. Further, it is noteworthy that the results obtained here support the findings of a recent US study ${ }^{30}$ of significant correlations on global and corresponding domains of health scores obtained between the NHP and FLP's US equivalent, the sickness impact profile. ${ }^{22}$ That this was for patients experiencing the same illness and that some of the correlations (for example, the correlation coefficient on the sleep domain) were almost identical to those obtained here, does add weight to the findings reported.

In relation to the use of weighting, it is seen that the correlations between the three measures remained high (see tables 2 and 3 ) regardless of whether weighted or unweighted scores were used. This implies that ostensibly the same rankings of quality of life were attained whether or not weighting was used - that is, that weights, in this instance, may be redundant. This is not to say, however, that the weighting of responses in the FLP and NHP surveys is always an unnecessary complication. Weighting permits a few questions to establish the severity of distress where in their absence a large number of questions may otherwise have to be used. For example, eight questions might cover the range of severity of a particular domain of health. All eight questions could be asked, each with an equal weight, and the total number of responses added to establish the degree of severity. Alternatively four questions with weights designed to reflect relative severity might be used to elicit (roughly) where on the same scale of distress the individual lay. While the weights here are not apparently performing this role, weighted and unweighted scores rank people similarly, this is not to say that this would be the case in other instances or that it would continue to be the case were the number of questions reduced further.

A point worth noting in relation to weights is the significant correlation obtained between the NHP and FLP scores for sleep, whether or not weights were used. $\mathrm{Kind}^{2}$ argues that as the NHP-established weights for sleep violate the goodness of fit statistics for the Thurstone paired comparison they "can have no legitimate basis". It could be inferred from this that use of these weights will result in erroneous conclusions. However, the results here indicate that the use of NHP weights does not result in values being produced which are at variance with those obtained using other techniques. In other words, while these weights may have no legitimate basis their use does not affect the overall conclusion in this case.

Table 4 highlights the fact that while in most instances the consistency of responses between questions on different instruments is high, this is not always the case. That is, the instruments are not interchangeable. In the case, for example, of the FLP statement, "I lie down to rest more often during the day", a positive response could be taken as implying that the patient tired easily. However, comparison with responses to NHP statements: "I'm tired all the time", "I soon run out of energy", and "everything is an effort" revealed that while an individual may "lie down more often during the day" (FLP), be "tired all the time" (NHP), and find "everything is an effort", it did not imply that they "soon (ran) out of energy" (NHP). That is, in terms of detecting deteriorating stamina as opposed to general lethargy NHP may be more discriminating. This only serves to reinforce the need to be careful in the interpretation of the results obtained using these instruments, a point emphasised by Ziebland, Fitzpatrick, and Jenkinson. ${ }^{32}$

\section{CONCLUSIONS}

The paper has shown that the three alternative instruments for assessing outcome used in this study consistently assessed the intervention to have improved aspects of quality of life. This consistency in results existed at the level of health domains and at the level of individual questions. The results show that this consistency was also apparent whether or not weighting was applied to responses. The findings indicate that in instances where one is interested in whether or not there was a significant change in health status and not simply the magnitude of a change, and where the instrument is applied to a group of patients suffering from the same illness, weights may not tell the researcher a great deal more about health status or changes in health status. Finally, the study found that a simple categorical scale captured changes in health/distress status in a manner consistent with longer questionnaires. This indicates that for validation purposes such scales may return useful measures at a lower cost than longer questionnaires. Care should, however, be exercised in the interpretation of results.

1 Department of Health. Working for patients. London: HMSO, 1989

2 Kind P. The design and construction of quality of life measures. York: Centre for Health Economics. Discussion Paper 43 3 Dunning M, Needham G, eds. But will it work doctor? London: King's Fund, 1993.

4 Rosser R, Watts V. The development of a classification of symptoms and sickness and its use to measure the output of a hospital. In: Lees D, Shaw S, eds. Impairment, disability and handicap. London: Heinemann, for the Social Science Research Council, 1974

5 Bardsley M, Beveridge $\mathrm{P}$, et al. CASPE/Freeman outcomes study: final report. London: Caspe Research, May 1991. 
6 Bowling A. Measuring health. A review of quality of life measurement scales. Buckingham: Open University Press, 1993.

7 Outcomes briefing Leeds: UK Clearing House for Information on the Assessment of Health Outcomes, 1994.

8 Somerville SM, Silver R, Patrick DL. Services for disabled people; what criteria should we use to assess disability? people; what criteria should we use

9 De Haan R, Horn J, Limburg M, Van Der Meulen J, Bossuyt P. A comparison of five stroke scales with measures of disability, handicap and quality of life. Stroke 1993;24(8): disability,

10 Jenkinson C, Wright $\mathrm{L}$, Coulter A. Quality of life measuremen in health care. A review of measures and population norms for the UKSF-36. Oxford: Health Services Research Unit, 1993.

11 O'Brien BJ, Buxton MJ, Patterson L. Relationship between functional status and health-related quality of life after myocardial infarction. Med Care 1993;31:950-5.

12 O'Boyle C, McGee H, Hickey A, O'Malley K, Joyce CRB. Individual quality of life in patients undergoing hip replacement. Lancet 1992;339:1088-91.

13 Nord E. An alternative to QALYs: the saved young life equivalent (SAVE). BMF 1992;305:875-7.

14 Vickery BG, Hays RD, Graber J, Rausch R, Engel Jr J, Brook RH. A health related quality of life instrument for prook RH. A health related quality of life instrument for patients evaluat

15 Cupples ME, McKnight A. A randomised controlled trial of health promotion in general practice for patients at high cardiovascular risk. BMF 1994;309:993-6.

16 EuroQol Group. EuroQol - a new facility for the measurement of health-related quality of life. Health Policy 1990 16:199-208.

17 Cupples ME, McKnight A, Normand C, O'Neill C. The effect of personal health education on the quality of life of patients with angina in general practice. Health Education fournal 1996 (in press)

18 Hunt S, McEwan P. The development of a subjective health indicator. Sociology of Health and Illness 1980;2:231-46.

19 Hunt S, McEwan P, McKenna S. Measuring health status: a new tool for clinicians and epidemiologists. $\mathcal{F} R$ Coll Gen Pract 1985;35:185-8.
20 Hunt S, McEwan P, McKenna S. Measuring health status. Beckenham: Croon Helm, 1986.

21 Bergner M, Bobbitt RA, Kressel S, Pollard WE Gilson BS, Morris JR. The sickness impact profile: conceptual formulation and methodological development of a health status measure. Int 7 Health Services 1976;6:393-415.

22 Patrick D. Standardization of measures: using scales developed in America in an English speaking country. In: Proceedings of health survey research speaking country. In: Proceedings of health survey research methods, third biennial conference. Hyat
of Health and Human Service, 1981.

23 Patrick D, Sittampalam Y, Somerville S, Carter W, Berner $M$. A cross cultural comparison of health status values. Am $\mathcal{F}$ Public Health 1985;71:1402-7.

24 Kapalan RM, Bush JW, Berry CC. Health status index: category ratings versus magnitude estimation for measuring levels of well-being. Med Care 1979;18:501.

25 Kind P, Rosser RM. The quantification of health. European fournal of Social Psychology 1988;18:63-77.

26 Hunt S, McKenna S, McEwan P. The Nottingham health profile user's manual. Manchester: Galen Research and Consultancy, 1989.

27 McKenna S, Hunt S, Tennant A. The development of a patient completed index of distress from the Nottingham health profile: a new measure for use in cost utility studies. fournal of Medical Economics 1993;6:13-24.

28 Greene WH. Econometric analysis. London: Macmillan, 1991

29 Ferguson B, Buxton M. Analysing NHP data: identifying common response patterns. Beckenham: Health Economics Research Group, Discussion Paper No 3, Oct 1986.

30 Visser MC, Fletcher AE, Parr G, Simpson A, Bulpitt CJ. Comparison of three quality of life instruments in subjects with angina pectoris: the sickness impact profile, the Nottingham health profile and the quality of well being scale. $\mathcal{F}$ Clin Epidemiol 1994;47:157-63.

31 Bergner M, Bobbitt RA. The sickness impact profile: development and final revision of a health status measure. Med Care 1981;19:787-805.

32 Ziebland S, Fitzpatrick R Jenkinson C Assessing short term outcome. Quality in Health Care 1992;1:141-2. 